\title{
(6)
}

\section{AS DIRETRIZES CURRICULARES DA ABEPSS E A TEMÁTICA FAMÍLIA}

\author{
Abepss curriculum guidelines and families theme \\ Claudio Henrique Miranda Horst ${ }^{1}$ \\ https://orcid.org/0000-0002-2226-4520
}

\begin{abstract}
RESUMO
A partir da lógica das diretrizes curriculares da ABEPSS, o objetivo deste artigo é apontar possibilidades para o estudo e o debate sobre a família na formação profissional em Serviço Social. Partimos do pressuposto de que as Diretrizes Curriculares exigem a apreensão dos diversos conteúdos que perpassam a formação/trabalho numa perspectiva de totalidade. Portanto, compreendemos que os fundamentos da profissão - expressos nas diretrizes curriculares possibilitam, através dos diferentes núcleos de fundamentação, a compreensão da família, por meio de fundamentos críticos, condizentes com o Projeto Ético-Político. Mediante indicações de como os componentes curriculares podem desenvolver as reflexões sobre família, apontamos estratégias possíveis de uma análise que rompa com o conservadorismo moral, religioso e com as expressões pragmáticas, no exercício profissional, sustentadas por experiências pessoais.
\end{abstract}

\section{PALAVRAS-CHAVE}

Família, Formação Profissional, Serviço Social.

\section{ABSTRACT}

The aim of the article is to point out possibilities for the debate about a families in professional training in Social Work based on the logic of the ABEPSS curriculum guidelines. We start from the assumption that the Curriculum Guidelines require the apprehension of several contents that permeate training / work in an open perspective. Therefore, we understand that the foundations of the profession - expressed in the curricular guidelines - make it possible from different nuclei of reasoning and the understanding of the families from critical foundations, consistent with the Ethical-Political Project. From indications on how the curriculum components can develop as reflections on the family, they point to strategies that allow an analysis that breaks with moral and religious conservatism and with pragmatic practical expressions in the professional practice sustained by individuals.

\footnotetext{
${ }^{1}$ Assistente Social. Professor do Departamento de Serviço Social da Universidade Federal de Ouro Preto. Doutor em Serviço Social (UFSC). Mestre em Política Social (UFES). Membro do "Livre Hermana" - Núcleo de Estudos e Pesquisas sobre Formação Social Latino-Americana e Brasileira e do Núcleo de Extensão e Estudos em Formação e Trabalho em Serviço Social (NEESFT). E-mail: claudiovasques1@hotmail.com.
}

DOI 10.22422/temporalis.2020v20n40p144-164

\section{$(\mathrm{cc}) \mathrm{EY}$}

A(s) Autora(s)/O(s) Autor(es). 2019 Acesso Aberto Esta obra está licenciada sob os termos da Licença Creative Commons Atribuição 4.0 Internacional (https://creativecommons.org/licenses/by/4.0/deed.pt_BR), que permite copiar e redistribuir o material em qualquer suporte ou formato, bem como adaptar, transformar e criar a partir deste material para qualquer fim, mesmo que comercial. O licenciante não pode revogar estes direitos desde que você respeite os termos da licença. 


\section{KEYWORDS}

Families, Professional Training, Social Work.

\section{INTRODUÇÃO}

$\mathrm{O}$ debate sobre a formação profissional ocupa um lugar central no Serviço Social brasileiro. Tal discussão tem como determinante central os desafios da política de educação e sua particularidade, no país, de capitalismo dependente, que implica em desafios maiores para a materialização do direito à educação e de uma formação profissional crítica. Dentro desse contexto, já complexo, que se situam os desafios para a materialização das diretrizes curriculares, de 1996, da Associação Brasileira de Ensino e Pesquisa em Serviço Social (ABEPSS).

Na esteira de uma crise estrutural do sistema do capital, nas palavras de Mészáros (2002), caracteriza-se como, crônica e permanente, são profundas as transformações no mundo do trabalho e nas políticas sociais, que tencionam e impactam, diretamente, a formação profissional por meio, principalmente, da supressão e mercantilização de direitos, onde os mesmos são indicativos de possíveis inflexões nas práticas profissionais. No que tange à política de educação superior, vivenciamos uma nova fase da contrarrevolução burguesa preventiva, conduzindo o aprofundamento da mercantilização da universidade pública e da ofensiva reacionária na educação (LIMA, 2019).

Diante dessa quadra histórica desafiadora para a formação profissional crítica, nossa preocupação, no presente ensaio, consiste em refletir sobre uma destas temáticas importantes para a formação profissional: o debate da temática família que, historicamente, vem sendo construído e enfrentado [ou não], a nosso ver, de forma problemática.

A necessidade de tal reflexão parte, dentre outros problemas, da afirmação que a teoria social de Marx, assim como a tradição marxista não possibilitam uma análise sobre a família. Tal afirmação (parte por desconhecimento - parte por negação) é problemática se a considerarmos como fundamento teórico-metodológico basilar de nosso projeto de formação.

Antes de mais nada, esta teoria articula-se sobre a perspectiva da totalidade: a sociedade é apreendida como uma totalidade concreta, dinâmica e contraditória, que se constitui de processos que, eles mesmos, possuem uma estrutura de totalidade - de maior ou menor

\footnotetext{
${ }^{2}$ É comum nos espaços da profissão, bancas, eventos, grupos de estudos, que tem proximidade com a temática em voga uma tendência próxima ao 'politicamente correto' de se corrigir o termo 'família' por 'famílias'. Adiantamos que, a nosso juízo, a defesa da diversidade familiar se constitui um posicionamento ético-político coerente com nosso código de ética. Nesse sentido, sempre que nos referirmos à família, no singular, estamos tratando da instituição, do microcosmo familiar (MÉSZÁROS, 2002). Famílias, no plural, às formas concretas de sua organização, que é diversa historicamente.
} 


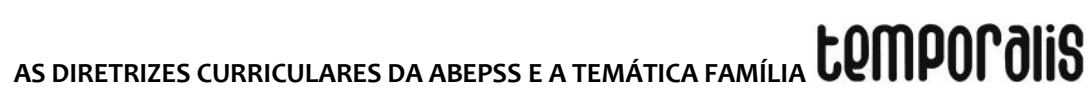

complexidade. A categoria da totalidade, nesta angulação, é simultaneamente a categoria central da realidade histórico-social e a categoria nuclear da sua re-produção teórica (NETTO, 1989, p. 93).

A ausência/negação da perspectiva de totalidade, comum na ciência do nosso tempo, vai materializando, concretamente, na vida e no entendimento dos sujeitos uma desconexão com o funcionamento geral da sociabilidade. "A sociedade aparece como um místico e obscuro poder, cuja objetividade fatalista e desumanizada se contrapõe, ameaçadora e incompreendida, ao indivíduo [...]" (LUKÁCS, 2012, p. 113), impactando, automaticamente: no entendimento da relação entre os próprios sujeitos e de suas famílias; e na compreensão da própria relação da família com a sociabilidade.

Nesse sentido, partimos do pressuposto de que as diretrizes possibilitam o estudo da família na perspectiva da totalidade. Mas, essa apreensão, a partir dos fundamentos do Serviço Social brasileiro, pode ser enriquecida e adensada pela profissão e, para isso, é importante avançarmos nos subsídios teóricos para a interlocução. A temática família deve perpassar o conjunto dos três núcleos das matérias e dos componentes curriculares, seja como item dos programas, seja como interface de diálogo.

Nossa preocupação com a temática condiz com um momento histórico, cujo recuo civilizatório repõe, novamente, no centro da história, a ideia da família como um microcosmo essencial para a saída da crise estrutural. Pelo menos dois exemplos corroboram tal ideia: o primeiro, trata-se do retorno fortemente no cenário político brasileiro da reafirmação de tal instituição como a responsável por colocar o país 'nos trilhos' da ordem moral, cívica e econômica'; e o segundo, pois, é o cenário de recrudescimento dos parcos direitos garantidos, que reafirmam, novamente, em detrimento destes, a família como a única responsável pela proteção social dos indivíduos 4 .

Afim de problematizar essas questões e oferecer subsídios para uma formação profissional alinhada com o projeto ético-político da profissão, organizamos o ensaio: no primeiro momento, apresentamos os pressupostos para o debate a respeito da família; no segundo momento, realizamos uma breve reflexão dos desafios das diretrizes curriculares na cena contemporânea; e, por fim, apontamos possibilidades para avançarmos nos estudos concernente à família, a partir das diretrizes curriculares na formação profissional.

\footnotetext{
${ }^{3} \mathrm{O}$ atual presidente do Brasil Jair Bolsonaro foi eleito com base em uma campanha que tinha como mote central - assim como seu governo - a defesa da família.

${ }^{4}$ A Secretária Nacional da Família Ângela Gandra explicitou a tendência familista do governo: "A proposta da Secretaria da Família é 'diametralmente oposta' à ideia de intromissão do Estado na esfera privada. $\mathrm{O}$ foco na família significa oferecer as bases para que a família possa consolidar-se internamente, sem que políticas públicas orientem suas decisões de forma pragmática e, na maioria das vezes, paternalista e ineficiente" (DESIDERI, 2019, não paginado).
}

Temporalis, Brasília (DF), ano 40, n. 20, p. 144-164, jul./dez.2020. | ISSN 2238-1856 


\title{
PRESSUPOSTOS TEÓRICO-METODOLÓGICOS PARA O DEBATE
}

Como pressuposto para o debate, na formação profissional, é necessário o enfrentamento de, pelo menos, três problemáticas: a) a que concebe a família como o objeto do trabalho profissional e/ou a referência para leitura da realidade; b) a que toma a família como algo 'dado', partindo do entendimento de haver um “consenso" sobre a concepção família; c) a que parte da experiência pessoal como referência para o trabalho profissional.

Tratada, em sua generalidade, a família vem sendo considerada, por boa parte dos profissionais, "base da sociedade". Nessa compreensão, as expressões da "questão social”, vivenciadas pelos indivíduos - entendidas como problemas -, derivam, essencialmente, da sua "desestruturação" familiar, da não possibilidade de suporte/apoio familiar e/ou, ainda, dos problemas comportamentais de desvio de caráter.

Tal entendimento é diametralmente oposto à direção social do projeto éticopolítico. A não compreensão da "questão social" e suas expressões como fundante da profissão podem situar a família como objeto de trabalho, passando esta a ocupar o ponto de vista para a leitura da realidade e, não, as determinações estruturais, a totalidade social.

Uma das inovações das diretrizes curriculares foi propor o trato do conjunto de conhecimentos indissociáveis para uma formação profissional crítica, de maneira articulada em núcleos de fundamentação. Mas não só, a definição da "questão social" e suas expressões, como centrais para o trabalho e para a formação, configuraram uma guinada teórico-crítica. "[...] o serviço social é reconhecido como uma profissão inserida na divisão sócio técnica do trabalho; e o trabalho como eixo fundante da sociabilidade" (ABEPSS, 1996, p. 6).

\begin{abstract}
A leitura da unidade articulada dos núcleos de fundamentação considera a questão social assentada na teoria do valor trabalho na sociedade capitalista, apreendida na lei geral da acumulação capitalista e suas refrações, objeto do trabalho profissional, nas particularidades sóciohistóricas da sociedade brasileira. Quando não se considera esses aspectos, o objeto da intervenção profissional deixa de ser as expressões da questão social e pode vir a se configurar a política social como objeto de trabalho (TEIXEIRA, 2019, p.83).
\end{abstract}

Ou, em detrimento da "questão social" e suas expressões, a ênfase - pelo menos no que tange ao trabalho profissional - pode recair na família, nas suas relações e nos comportamentos entre seus membros -, configurando como objeto do trabalho profissional a própria instituição família ${ }^{5}$. Por isso, o primeiro pressuposto

\footnotetext{
${ }^{5}$ Historicamente, defesas conservadoras sinalizam que o objeto do trabalho deve ser as relações familiares em si, relações "intrafamiliares" (MIOTO, 2004; 2010). Contudo, outras tendências vêm sendo reatualizadas, e defendendo a resolução/mediação de conflitos, o empoderamento dos indivíduos, a resolução dos problemas psicossociais, etc. como objeto do trabalho. Ver: VASCONCELOS, 2015.
} 
para o debate, na formação profissional, é reafirmarmos que as expressões da "questão social" atravessam as famílias e seus indivíduos, os quais são pertencentes a uma classe social.

A leitura da realidade, reduzida ao âmbito do indivíduo-família, impossibilita, no exercício profissional, identificarmos as causas subjacentes da estrutura do sistema do capital e interpela, dessa maneira, os sujeitos e suas organizações familiares. A ausência da perspectiva de totalidade contribui para a moralização, culpabilização, responsabilização dos indivíduos e suas famílias em detrimento dos determinantes estruturais, da luta de classes. Isso pode resultar na concepção de família como produtora de patologias (MIOTO, 2004).

As/os assistentes sociais foram convocadas/os, desde a gênese da profissão, a trabalhar no âmbito da produção e reprodução da vida da classe trabalhadora - cuja expressão particular da família se mostra como instituição universal indispensável à reprodução capitalista junto aos indivíduos - sustentada por uma função política de cunho educativo, moralizador, disciplinador que a legitimava enquanto profissão (IAMAMOTO, 2013).

\begin{abstract}
Além da noção de comunidade [...], merece destaque a ênfase na formação social, moral e intelectual da família, considerada como célula básica da sociedade. Trata-se de um trabalho "educativo" entre a família operária, especialmente entre os mais carentes que têm acesso aos equipamentos socioassistenciais, com o objetivo de reforçar o núcleo familiar e integrar seus membros à sociedade. Buscam-se na história familiar os elementos explicativos de comportamentos individuais 'anômalos' ou 'desviantes' de um padrão tido como 'normal'. A família, como grupo social básico, é erigida como núcleo do trabalho profissional e como referência para a apreensão da vida em sociedade, em contrapartida às classes sociais (IAMAMOTO, 2013, p. 33, grifos nossos).
\end{abstract}

Uma formação profissional crítica precisa enfrentar a compreensão da família como "núcleo do trabalho profissional" e/ou como "referência para a apreensão da vida em sociedade". Além disso, o debate a respeito à família, na formação profissional, deve ultrapassar os principais limites das análises da família, que não aprofundam o entendimento da própria instituição.

Ponderamos tais análises como limitadas, elas tomam tal instituição como algo 'dado' e encontra raízes em dois espaços de produção e discussão acerca da família:

a) Na defesa da diversidade familiar ("novos arranjos familiares") como a "crítica máxima" a ser elaborada pela profissão a partir da tradição marxista.

A diversidade familiar é um tema importante de ser discutido para o exercício profissional. É preciso conhecê-los como estratégias para confrontar o discurso moral do modelo nuclear patriarcal burguês como único possível. Além disso, defende-lo, no plano individual, pode fazer com que os indivíduos possam ter o direito de partilhar a vida, as vivências afetivo-sexuais com quem optarem. No entanto, o formato assumido do debate pode nos levar, primeiro, a uma idealização de certos modelos familiares, por ter 'rompido' com o padrão burguês. Quando, na 
verdade, independente da organização, a família, no modo de produção capitalista, apresenta particularidades, e diferente de ser sinônimo apenas de amor e proteção, está fadada a reproduzir violências, opressões e a inculcação dos valores dominantes. Ou seja, independente do modelo, é uma instituição contraditória ${ }^{6}$.

Segundo, as diversas formações familiares aparecem como "novos modelos" (por vezes datados da década de 1960 em diante) e não, apenas, com maior visibilidade. Desistoricizando a vivência, ao longo da história das mais diversas formas de organização familiar, - pois partem de uma recuperação histórica etapista, cronológica, que não recorre a concepção de história do materialismo histórico dialético (ENGELS, 2012).

Contudo, o ponto central são os limites apresentados, no que tange ao desvendamento da instituição em si, a compreensão de família. Sua gênese, natureza, particularidades assumidas em cada modo de produção e o seu momento predominante na sociedade burguesa. Muitas vezes o modelo hegemônico da família nuclear patriarcal burguês aparece como a-histórico, e os estudos focam em um modelo particular, tomando o entendimento da instituição como algo dado.

Tanto por ser tomada como algo 'dado', quanto por não ser capaz de romper com as expectativas sociais sobre as mesmas, pois, apesar de contribuir para o consenso de que as famílias se transformaram ao longo dos anos - é comum, no trabalho profissional, a exigência de padrões de funcionalidade, principalmente, referente aos papéis tidos como masculinos e femininos (MIOTO, 2004). Essa discussão precisa avançar nessas mediações.

b) Na discussão da família aprisionada ao debate da política social.

Não temos dúvida que, hoje, o acúmulo teórico, presente na profissão, tem possibilitado a crítica à família. Ele advém do debate construído em torno do seu lugar e de sua relação com a política social. Na verdade, a possibilidade de crítica à tendência familista das políticas e dos serviços, bem como do trabalho profissional, nessa perspectiva, deve-se ao acúmulo do debate via política social (MIOTO, 2015).

A política social é resultada das formas de o Estado enfrentar a "questão social" e as suas expressões. Nesse sentido, a relação da "questão social" com a profissão é materializada pela mediação das políticas sociais, possibilitando um amplo acúmulo teórico concernente à política social, particularmente em torno da seguridade social. No entanto, tal acúmulo, ainda, não pode ser visto no que tange aos debates em torno do exercício profissional nas políticas sociais.

\footnotetext{
${ }^{6}$ Conforme nos alertou Mészáros: “Pares isolados podem ser capazes de ordenar (o que certamente o fazem) seus relacionamentos pessoais em verdadeira igualdade. Na sociedade contemporânea existem até mesmo enclaves utópicos de grupos de pessoas que integram comunitariamente e podem se afirmar engajados em relações interpessoais não-hierárquicas humanamente satisfatórias e em formas de criar os filhos muitos diferentes da família nuclear e suas fragmentações. Não obstante, nenhum desses dois tipos de relação pessoal pode se tornar historicamente dominante no quadro do controle sociometabólico capitalista" (MESZÁROS, 2002, p.270).
}

Temporalis, Brasília (DF), ano 40, n. 20, p. 144-164, jul./dez.2020. | ISSN 2238-1856 


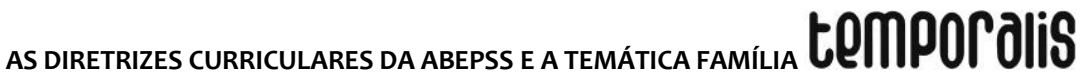

Conforme sabemos, o perfil profissional exigido pelas políticas é o do técnico generalista, o que "faz de tudo um pouco". Por isso, a necessidade de avançarmos na compreensão de que falar da política social não é o mesmo que falar do exercício profissional na política social (GUERRA, 2019).

O desafio da formação profissional é realizar essa distinção clara entre política e a profissão, explicitar as diferenças, no intuito de demonstrar a autonomia necessária que deve haver da profissão em relação às políticas sociais e não apenas às de seguridade social. Contudo, ao mesmo tempo, a formação deve estabelecer os nexos e as conexões, evidenciando as mediações constitutivas de ambos e sua necessária articulação. O que as poucas pesquisas não têm sido capazes de problematizar é que há distinções de conteúdo (teórico e ético-político) entre as demandas e requisições institucionais e as atribuições e competências da profissão (GUERRA, 2019, p. 116).

Com isso, queremos chamar atenção de que é comum, nas disciplinas sobre política social/seguridade social, nas próprias disciplinas de família, nos cursos de extensão, na elaboração de documentos do estágio e etc., a opção pelo debate e estudo apenas dos marcos normativos e legislações. Sem dúvida é essencial para o trabalho profissional, mas devem ser mediados pela crítica qualificada aos mesmos, dialogado com a produção teórica crítica da profissão. No entanto, muitas vezes, os marcos normativos ganham centralidade nos espaços e são apresentados como se possuíssem os mesmos fundamentos da profissão.

Dessa seara deriva uma questão central, na produção teórica, concernente à família a partir da política social: o não tratamento do debate da família, em si, mais uma vez tratada como um 'dado', do qual se supõe que já sabemos de qual instituição se trata. Ou seja, é visto como consenso de como surgiu, como se desenvolveu em cada momento particular da história da humanidade. Quando muito, recupera-se a reflexão das transformações nas famílias por meio da tendência identificada acima (sob uma história cronológica dos modelos familiares). Por isso, a ideia da instituição persiste, "[...] vista como a célula básica da sociedade, a família se insere na dinâmica social de forma inquestionável, ou seja, não se levantam dúvidas quanto a pertinência dessa instituição que é vista como um 'dado', no sentido durkheimiano do termo" (SILVA, 1982, p.16).

Ainda não é comum a problematização crítica ontológica em relação à família, advinda das produções teóricas da política social e, muito menos, dos próprios documentos das políticas (HORST, 2018). Pelo contrário, os referencias da política social, além de profundamente ecléticos, por vezes, expressam tendências da terapia familiar, apresentando metodologias de trabalho como aparentemente neutras, descoladas de tendências teóricas e de método ${ }^{7}$.

\footnotetext{
${ }^{7}$ Não temos espaço no presente artigo para adentrarmos na direção social exigida pela PNAS para execução da metodologia de trabalho social com famílias. Ver: (SILVEIRA JUNIOR, 2016). Destaca o autor: "A metodologia de trabalho social proposta demonstra pautar-se por uma pedagogia empresarial para dirigir as formas sociabilidade, os projetos e as atitudes das famílias e indivíduos das classes subalternas na situação de pauperismo. "[...] Consiste numa forma capilar de infiltração da racionalidade capitalista no cotidiano da reprodução familiar e pessoal dos dominados, tendendo a
} 


\section{Por fim, a tendência que parte das experiências individuais das/dos sujeitos.}

É importante assinalar que tal tendência - apesar da necessidade de avançarmos nas pesquisas - não nos parece ser discutida e defendida, deliberadamente, nos espaços de formação profissional em Serviço Social. No entanto, é fortemente presente no trabalho profissional. A tendência pragmatista tem mais a ver com a ausência do debate na formação, do que pelo debate em si. Conforme as pesquisas demonstram (HORST; MIOTO, 2017), a ausência do debate na formação tem levado: a) a reprodução do moralismo, do conservadorismo a partir da adoção de referências pessoais e idealizadas; b) o recurso a outras perspectivas como a psicanálise, e as mais diversas formas de terapia familiar ${ }^{8}$, o diálogo direto com a orientação sistêmica.

As experiências individuais em família são diversas, apesar do caráter comum, possuem dinamicidades próprias e não podem ser acionadas como referência para o trabalho profissional, com vistas a moralização das famílias atendidas. Já que entra no circuito do trabalho profissional, a comparação da família atendida com "minha experiência pessoal" - ou com famílias próximas - e destoando daquilo que se toma como "normal" e "estruturada", as famílias atendidas vão sendo classificadas, por meio de comparação, entre 'boas' ou 'más', 'estruturadas ou desestruturas'.

Com base nas reflexões de Barroco (CFESS, 2016), sinalizamos essa tendência como própria da vida cotidiana, do senso comum, expressão de uma das suas características: o subjetivismo, em que “[...] os sentimentos e opiniões de indivíduos e grupos são reproduzidos como se fossem universais e valessem para todos os tempos e situações" (CFESS, 2016, p. 9).

Como observamos, as características do senso comum são inerentes à dinâmica da vida cotidiana. Ou seja, a heterogeneidade, a imediaticidade, a empiria e a ultrageneralização da vida cotidiana alimentam o conhecimento do senso comum, baseado em relações de causa e efeito, em juízos imediatos que generalizam opiniões, sentimentos e visões de mundo particulares, tratando-as como universais e verdadeiras, e, ao mesmo tempo, desconectando as situações da história. Portanto, o problema do preconceito não reside na existência de juízos provisórios, pois eles são inevitáveis na dinâmica da vida cotidiana e porque todo contato com a realidade põe em movimento nossa experiência de vida, incluindo conhecimentos e julgamentos de valor. O problema está na permanência e rigidez dos juízos provisórios e na negação das mediações que podem confirmá-los ou não (CFESS, 2016, p. 10, grifos nossos).

responsabilizá-los por sua situação de vida. Combinados com o 'enfoque nas capacidades', as noções de 'ativos e capital social' descarrega grande peso nas dimensões comportamentais, psicossociais e educacionais, tanto para a determinação das causalidades da pobreza, quanto para sua superação, mistificando os condicionamentos de classe e os fundamentos histórico-estruturais que a alicerçam" (SILVEIRA JUNIOR, 2016, p. 317).

${ }^{8}$ Vale destacar que essa abordagem, no âmbito do exercício profissional, é vetada, conforme determina a resolução ${ }^{\circ}$ 569, de 25 de março de 2010 do CFESS.

Temporalis, Brasília (DF), ano 40, n. 20, p. 144-164, jul./dez.2020. | ISSN 2238-1856 
Frente a essas "tendências", apostamos -uma das possíveis estratégias - no avanço de estudos, pesquisas e debates nas salas de aulas, no entendimento da família na perspectiva de totalidade, resgatando sua gênese, seu desenvolvimento e sua particularidade no sistema do capital. Tal compreensão é importante num cenário em que a ciência social burguesa tem defendido a eternização da família nuclear patriarcal burguesa, logo, do capital. Mais do que isso: projeta sua origem na natureza ou no divino, por intermédio de uma leitura da realidade sustentada numa ontologia religiosa (LUKÁCS, 2012).

$\mathrm{Na}$ negação do debate em torno do surgimento da família (sua gênese e desenvolvimento), há elementos para indicar o conservadorismo presente na profissão. Por isso, o ponto de partida na formação profissional precisa captar “[...] as mediações necessárias para avançar na desnaturalização e eternização da família, apontando principalmente, vincada no projeto profissional crítico, suas contradições e a necessidade de sua superação" (HORST, 2018, p.187), a partir de uma crítica ontológica.

\section{POSSIBILIDADES PARA O ESTUDO SOBRE A FAMÍLIA FUNDAMENTADA NA LÓGICA DAS DIRETRIZES CURRICULARES}

Segundo lamamoto (2014), o processo de mutação pela qual a formação em Serviço Social, no Brasil, vem passando é condicionado por diversos fatores, entre eles: a prevalência e expansão acelerada de instituições privadas não universitárias, com destaque para o EAD (educação a distância), que colocam em questão o tripé ensino, pesquisa e extensão; a precarização das condições de trabalho docente; a mudança no perfil socioeconômico das/dos discentes. Tais fatores apresentam implicações na qualidade da formação, com forte ênfase no treinamento e aligeiramento no trato da teoria. Portanto, “[...] a massificação e a perda de qualidade da formação universitária facilitam a submissão dos profissionais às demandas e 'normas do mercado', tendentes a um processo de politização à direita da categoria" (IAMAMOTO, 2014, p.629).

Assim sendo, as transformações societárias alteraram, profundamente, o campo profissional do Serviço Social, objetivadas na conformação de um novo perfil profissional, impactam, diretamente, na possibilidade de respostas alternativas às demandas e às necessidades sociais, apresentadas no cotidiano do trabalho, mediadas pelo projeto ético-político. Nesse processo, algumas contradições se explicitam, pois, ainda que a profissão tenha se constituído como área de conhecimento, persistem fragilidades em relação a certas temáticas como os instrumentos e técnicas, como, por exemplo, a própria temática família e o trabalho profissional com as famílias (MIOTO, 2010).

Por isso, o não enfrentamento (ou negação) da temática, diante do avanço das políticas sociais, focalizadas e centralizadas nas famílias - com um forte retorno das metodologias de trabalho com famílias, e a precarização da formação e do trabalho profissional- podem, somados, colocar desafios que, se não enfrentados, contribuem para a politização à direita da categoria profissional.

Temporalis, Brasília (DF), ano 40, n. 20, p. 144-164, jul./dez.2020. | ISSN 2238-1856 
Diante essa conjuntura, apontamos a possibilidade, em aberto, do avanço de tendências conservadoras, algumas discutidas no presente texto, como, por exemplo, o ponto de partida da própria experiência individual das/os profissionais. Por isso, o avanço da pedagogia do EAD é preocupante, considerando essa dimensão como valorizada para essa formação.

A dimensão subjetivista é crucial para a consolidação de uma ação pedagógica compreendida como eficaz, na medida em que os estudantes precisam desenvolver técnicas e formas de estudos que reforcem a prática do 'aprender a aprender', aliado à construção do conhecimento (confundido com informação) partindo da experiência vivida do sujeito: de suas aspirações, desejos, sentimentos, sensibilidades, sob o manto de um humanismo abstrato, destituído de um sentido histórico (SILVA; AMARAL, 2019, p.447).

Conforme estamos apontando ao longo do texto, são os elementos da própria conjuntura, permitindo-nos explicitar e compreender os desafios da apropriação do fundamento teórico e da lógica que sustentam nosso projeto de formação, que acabam comprometendo a unidade articulada dos núcleos presentes nas diretrizes. Tais núcleos são tomados na formação ${ }^{9}$ como estanques, desarticulados, de forma hierárquica, e não como níveis distintos de abstração do tratamento do exercício profissional em seus fundamentos.

Sendo assim, consideramos, de ordem prioritária, o fortalecimento da direção social estratégica, retomando os fundamentos da profissão, tendo como base as diretrizes expressas na concepção dos três núcleos.

\begin{abstract}
A análise dos Fundamentos do Serviço Social como unidade articulada dos Núcleos de Fundamentação tem particularidades na formação e no trabalho e cabe aqui evidenciar cada uma delas. Um dos objetivos na formação é que a/o discente tenha a capacidade de apreender que tal unidade articulada se expressa como Fundamentos do Serviço Social, portanto, é o ponto de chegada ao final da formação profissional. Mas, no trabalho profissional tal unidade é o ponto de partida, sem a qual o trabalho profissional não ocorre sob a direção social crítica construída pela profissão. No trabalho profissional esta unidade articulada dos conteúdos dos Núcleos de Fundamentação se expressa como ponto de partida, pois toda exercício profissional cotidiano deve ser prenhe do percurso metodológico e do arsenal de categorias que sustentam a lógica das Diretrizes Curriculares, ou seja, da lógica crítico-dialética (TEIXEIRA, 2019, p. 83, grifos do autor).
\end{abstract}

Nesse sentido, com base na proposta do presente ensaio, passaremos para uma discussão in loco, pensando, concretamente, as diretrizes. Essa lógica expressa um conjunto de conhecimentos necessários para subsidiar o trabalho profissional e, para isso, é necessário assegurá-los na formação profissional.

\footnotetext{
9 “E no que tangencia ao trabalho profissional, a fragmentação dos núcleos de fundamentação que formam assistentes sociais acarreta, também, um trabalho profissional fragmentado, pois as/os assistentes sociais não conseguem acionar uma complexa gama de conhecimentos, que deveriam ser apreendidos na formação, necessários para a construção da intervenção profissional. Tais elementos reafirmam a relação trabalho e formação na unidade articulada dos núcleos" (TEIXEIRA, 2019, p. 39).
}

Temporalis, Brasília (DF), ano 40, n. 20, p. 144-164, jul./dez.2020. | ISSN 2238-1856 
É comum, nos debates curriculares e/ou nas revisões curriculares, a discussão sobre família girar em torno da necessidade de se manter uma disciplina específica do tema família ou de trabalhar a temática incorporada como um tópico dentro da ementa das disciplinas de política social de assistência social e/ou de gênero. Para além do formato do debate assumido no currículo - disciplina (obrigatória ou não), oficina, etc., as sugestões apontadas voltam-se à preocupação com a direção teórica-metodológica e ao enfrentamento das tendências apresentadas no presente ensaio, entre outras. Não é redundante reforçamos que não temos a pretensão de definir ou estabelecer o lugar ou como o debate deve ser feito, mas tão apenas contribuir para dar visibilidade a algumas possibilidades, diante da trajetória de pesquisa e trabalho com a temática.

Compreendemos o debate acerca da família, na formação profissional na direção dos fundamentos do Serviço Social, algo a ser articulado aos três núcleos de fundamentação. Por isso, cada matéria e seus desdobramentos como componentes curriculares - disciplinas, laboratórios, oficinas e etc., devem carregar, em si, a explicitação da unidade dos três núcleos, ainda que: "os conteúdos das matérias estão imediatamente interligados a um determinado núcleo de fundamentação, só são considerados conteúdos dos fundamentos do Serviço Social quando mediados pelos demais, sem perder as particularidades que cada matéria comporta" (TEIXEIRA, 2019, p.88).

Dito isto, nossa exposição se desmembra em duas sugestões: a) no primeiro momento, selecionamos, aleatoriamente, duas matérias sugeridas pelas diretrizes e problematizamos as possibilidades contidas nelas para o debate em relação à família; b) no segundo momento, elaboramos reflexões em torno da possibilidade de enfrentarmos a temática via um componente curricular em particular- os laboratórios.

\section{MATÉRIA: POLÍTICA SOCIAL}

Ementa: As teorias explicativas da constituição e desenvolvimento das políticas sociais. A questão social e desenvolvimento do sistema brasileiro de proteção social. Formulação e gestão das políticas sociais. A constituição e gestão do fundo público. O papel dos sujeitos políticos na formulação das Políticas Sociais Públicas e Privadas. As políticas setoriais e a legislação social. A análise comparada de políticas sociais. O papel das políticas sociais na constituição da esfera pública e o significado do debate público e privado. As novas formas de regulação social e as transformações no mundo do trabalho (ABEPSS, 1996, p.16).

Os itens da ementa da matéria política social -podem ser desdobrados no currículo nas mais diversas formas de componentes curriculares - apresentam inúmeras frentes que podem, como interface de diálogos, possibilitar o estudo da temática família, destacaremos alguns.

Ao recuperarmos o percurso da política social, ao longo da história, e demarcarmos a concepção de política social, bem como de proteção social, cabe destaque a 
forma de incorporação - ou não - das famílias nos mais variados sistemas de proteção social. Nesse sentido, há a possibilidade de se desmembrar o próprio entendimento da família - ou seja, qual o seu lugar na reprodução social, a particularidade assumida a partir da divisão social, técnica, racial e sexual do trabalho e com o surgimento da propriedade privada - para entender a centralidade que a mesma assume no capitalismo, e, paralelamente, na política social.

O desvendamento da instituição, em si, possibilita entender as formas das diversas experiências como do Estado de Bem Estar Social, da União Soviética, bem como as concepções do liberalismo e do neoliberalismo concebem e incorporam a família no sistema de proteção social, da relação desta com o Estado, com as políticas sociais.

Outra chave central é intermediada pelas reflexões acerca da "questão social" e o sistema de proteção social brasileiro, a possibilidade que se abre no momento de se recuperar os elementos sócio-históricos de nossa formação social, de demonstrarmos a profundidade do caráter familista de nossa sociedade (HORST et al, 2018).

Diante da constituição de um capitalismo sui generis (MARINI, 2011), dependente, e da impossibilidade - por vias institucionais - de políticas sociais universais, refletirmos sobre a perversidade da incorporação da família em nossa realidade. Esta, ainda sob o discurso da "proteção social", será, altamente, sobrecarregada e responsabilizada pelo Estado e os serviços sociais, particularmente as mulheres.

Quaisquer que sejam os desdobramentos da matéria política social, no currículo, sua interface central com a temática família será a contribuição crítica ao familismo. As políticas sociais, referentes às famílias, constroem um conjunto de instrumentos e normativas que buscam fortalecer as funções sociais ligadas ao modelo patriarcal nuclear burguês. A tendência familista concebe a família como a principal instância de provisão de bem estar social, de proteção, por concebê-la uma instituição, naturalmente, responsável pelo cuidado.

De acordo com Mioto (2010; 2015), familismo é um padrão de inter-relação na sociabilidade, em que, nos sistemas de proteção social, a família é a principal responsável. No âmbito do cotidiano, uma rede de mulheres é responsabilizada e responde pelo trabalho familiar não pago, de cuidados aos dependentes e outros membros.

Pensando o papel dos sujeitos políticos, também pode ser recuperado o papel das famílias nas lutas em defesa das políticas públicas e privadas, desfazendo a aparente imagem da família, apenas, como uma instituição conservadora, ou do exercício da sua função protetiva, reduzido a tarefas a serem cumpridas pelos seus membros no interior da casa. Algumas experiências, no campo da política de saúde mental, podem ser riquíssimas para pensar estratégias para o trabalho profissional, alicerçadas das associações organizadas pelas mesmas na luta por direitos (NISIIDE; SILVA, 2019). Aliás, conforme destaca Falquet (2006), “[...] nos movimentos rurais, campesinos e/ou indígenas, a mobilização simbólica e material da família é uma das

Temporalis, Brasília (DF), ano 40, n. 20, p. 144-164, jul./dez.2020. | ISSN 2238-1856 
chaves do funcionamento, e até mesmo do sucesso do movimento" (FALQUET, 2006, p. 211).

Ao mesmo tempo, a crítica ao familismo pode ser acionada nos momentos de leituras e estudos das legislações sociais das mais variadas políticas setoriais. Os estatutos da criança, do idoso, da juventude, entre outros, precisam ser problematizados no que se refere à forma compreendida de família e as expectativas criadas sobre as mesmas. Tal reflexão deve ser antecedida pelos questionamentos: quem protege a família? O município conta com uma rede de políticas públicas e sociais como suporte às famílias da classe trabalhadora, para que as mesmas tenham condições de protegerem seus membros?

Torna-se necessário o avanço do trabalho com as famílias nas demais políticas sociais: a saúde, a educação, a assistência estudantil e a área sociojurídica e outras, que atuam fortemente com as famílias. Por isso, a presente matéria pode ser central na contribuição do desvendamento das tendências predominantes de incorporação das famílias no campo da política social. Segundo Mioto (2010), a grosso modo, pode ser resumida em duas tendências: a familista e a protetiva.

\section{MATÉRIA: FORMAÇÃO SÓCIO-HISTÓRICA DO BRASIL}

Ementa: A herança colonial e a constituição do Estado Nacional. Emergência e Crise da República Velha. Instauração e colapso do Estado Novo. Industrialização, urbanização e surgimento de novos sujeitos políticos. Nacionalismo e desenvolvimentismo e a inserção dependente no sistema capitalista mundial. A modernização conservadora no pós-64 e seu ocaso em fins da década de 70. Transição democrática e neoliberalismo (ABEPSS, 1996, p.16).

Diante das diversas formas que a matéria em questão pode se desdobrar no currículo abre-se espaço para recuperarmos: os modos de organização, os valores reproduzidos pelas mesmas, bem como a arquitetura do familismo a partir da nossa formação sócio-histórica. As diferentes funções da família da classe burguesa e da família da classe trabalhadora revelam estratégicas na constituição das relações capitalistas no Brasil (HORST et al., 2018).

$\mathrm{Na}$ busca pela apreensão dos movimentos que permitiram a consolidação de determinados padrões de desenvolvimento capitalista, no Brasil, a temática família é uma chave importante para desvendamento. A importância da família, assumida no período colonial para organização da vida social; ou o lugar ocupado pela família na construção da ideia de nação, fortemente acionada no momento histórico em que se estruturam as relações entre público e privado, no país. Conforme Costa (2004) constatou essas são algumas questões que podem ser recuperadas já que a família nuclear patriarcal é vista de maneira a-histórica e única organização possível como condição para o país alçar a condição de nação. 
No tocante à formação social, outra chave-motriz é recuperar a dimensão do racismo, o qual estrutura as relações familiares no Brasil. Nesses termos, aprofundar o processo histórico de constituição das famílias, em nosso território, a partir da categoria racismo, possibilita o enfrentamento no cotidiano profissional de idealizações em torno de um modelo familiar impossibilitado, estruturalmente, de se constituir no capitalismo dependente. Ao mesmo tempo, possibilita enfrentarmos a permanência, no cotidiano dos serviços, da concepção conservadora de famílias desestruturadas, negligentes, incapazes, tendo o racismo como uma determinação central.

Os determinantes estruturais, o colonialismo e a escravidão, forjaram um processo de desigualdade e destruição das organizações originárias dos povos indígenas e negros, ao mesmo tempo, de imposição ideológica de um tipo ideal. Essas experiências destruíram, largamente, os diversos modos de constituir famílias dos povos originários. A população negra há, antes de tudo, a partir do processo de mercantilização, da venda dos corpos, dos indivíduos negros escravizados, impossibilidades concretas para que a família ideal seja uma realidade.

Trata-se de um processo de brutalização e desumanização tamanha, constituindo o processo de escravidão e que, no pós-abolição, configura-se, perversamente, em uma exigência para que esses sujeitos constituam família a partir de certos padrões, já que "[...] o projeto societário imposto pelas elites brasileiras no pós-abolição, indubitavelmente, tinha a intenção de tornar o país moderno, à luz do referencial europeu" (ALMEIDA, 2017, p. 34).

Nesses termos, recuperar a dinâmica da organização da família, a começar da instituição do trabalho livre, leva-nos a pensar como esses sujeitos são colocados em uma situação de marginalização. A família racializada no processo pós-abolição precisa ser pensada desde as condições objetivas de suas vidas, ou seja, pensadas a partir da própria estrutura de organização do capital que inviabilizará a família idealizada. Há especificidades no padrão de inserção na sociedade, na relação com o consumo, são inviabilizadas no acesso às políticas sociais. Ainda que, historicamente, as famílias negras construíssem estratégias próprias de sobrevivência e de formas de resistências (DAVIS, 2016).

Ao recuperarmos os vínculos do escravismo, com o tempo presente, é possível desvendar o genocídio da população negra, o encarceramento e seus impactos nas famílias, donde o neoconservadorismo e a ausência de uma leitura de totalidade vem arquitetando essas famílias como desestruturadas ${ }^{10}$. Conforme Almeida (2017,

\footnotetext{
${ }^{10}$ Conforme destaca Goldani, são, em suma, a maioria das famílias formadas por mães e filhos sem cônjuge, são a maioria, em probabilidade, de serem pobres ou indigentes. O tempo de permanência na condição de não casadas é maior entre as mulheres negras, assim como o menor tempo de expectativa de vida, quando comparado com as mulheres brancas (GOLDANI, 2005). A perversidade se encontra no apagamento do processo sócio-histórico e na redução das expressões da "questão social" vivenciadas pelas famílias negras como um problema de suas estruturas, construindo inclusive teorias de uma suposta "deterioração interna da família negra", que subestima entre outros elementos a própria capacidade do povo negro de resistir (DAVIS, 2016).
} 
p.43), "em uma sociedade racializada e fortemente marcada pela tradição colonial, o racismo opera, dentre outras formas, para destituir sua vítima da condição humana" e nos termos que estamos tratando para perpetuar o mito da desestruturação familiar, ao considerarmos o racismo uma coluna central de sustentação desse mito.

Enfrentar essa discussão na formação profissional se coloca urgente, diante da permanência no trabalho profissional da moralização, criminalização, desqualificação como desestruturadas - por não obedecerem a padrões morais dominantes - das famílias atendidas por nós. Tal dinâmica integra, no cotidiano do trabalho, o processo de controle das frações da classe trabalhadora seja encarcerando, matando e/ou institucionalizando crianças e adolescentes negros (EURICO, 2018).

Nesse motim, é possível recuperar a dialética entre a ideologia do trabalho e a ideologia da família, ou seja, a tendência construída para assegurar a lógica liberal do trabalho e da meritocracia do discurso do enriquecimento por esforço individual seria possibilitada, segundo a formação de uma família ideal, a patriarcal burguesa. No esforço de apreender as relações entre Estado e sociedade, tais características constituem parte dos mecanismos políticos e institucionais construídos e puderam ser materializados em políticas sociais.

Mas, sem dúvida, são também os diversos aspectos da processualidade histórica que poderão demonstrar em decorrência da legitimação, por exemplo, da figura do patriarca na formação social brasileira, a própria reprodução do coronelismo político se reatualiza com fortes traços, permitindo, até o presente, um conflito no âmbito da política pública do que são direitos sociais, benesses e caridade. Esse traço se relaciona com a ideia da divisão da vida em espaços públicos e ditos privados. Ao considerarem a família como responsável pelo espaço privado, como se fosse deslocado da sociabilidade, define-se o que compete a mulheres e aos homens.

Portanto, na relação da formação social brasileira, a família e as reflexões patriarcais de gênero e o lugar das mulheres são fortes temáticas para desvendar o lugar que o sistema sócio metabólico do capital concebe às mulheres. Em outras palavras, o lugar relegado às mulheres diz respeito a forma de organização da família no capitalismo, a partir do surgimento da família monogâmica, conjuntamente ao Estado e a propriedade privada.

Traços gerais de nossa cultura, como o autoritarismo, o conservadorismo, o paternalismo, o próprio patriarcalismo e a estrutura heterossexista são marcas expressadas na política social, por meio da proposta familista. Por isso, a temática da família pode proporcionar uma abertura para a discussão dos valores reproduzidos pelas famílias atendidas por nós, de como pensar um trabalho junto às mesmas a partir dos princípios éticos profissionais. 
Por fim, sabemos que a preocupação em desvendarmos desde a formação profissional aos aspectos da realidade brasileira é condição central para enfrentar as exigências históricas postas à profissão. Ainda que muitos traços das novas demandas carreguem, em si, dialeticamente, os traços de um passado histórico. $O$ traço familista é uma dessas características, fortemente presente na formação social. A possibilidade de conhecimento, em profundidade, das ações das classes trabalhadoras, suas condições de vida e de trabalho, seus modos de vida, podem e devem ser desvelados a partir do trabalho com famílias.

Os elementos da realidade, como alto índice de violência contra crianças, idosas, mulheres, a opção por não viver em família, como parte da população em situação de rua, ante a possibilidade de uma moralização das famílias e dos sujeitos demostram uma vez mais a contradição e o estranhamento próprio das relações familiares na ordem burguesa. Trata-se, pois, de uma realidade cujos determinantes são expressões concretas de uma sociedade que, em sua particular formação social, é antipopular, antidemocrática e se mantém alheia às reais necessidades de seu povo.

\section{COMPONENTE CURRICULAR: LABORATÓRIOS}

Segundo as diretrizes curriculares, os laboratórios (e as oficinas) são "espaços de vivência que permitam o tratamento operativo de temáticas, instrumentos e técnicas, posturas e atitudes, utilizando-se de diferentes formas de linguagem" (ABEPSS, 1996, p.15). Nesse sentido, apontamos que esse componente pode se constituir em espaço estratégico, no currículo, para a discussão família e o exercício profissional com elas.

No caso da opção pela experiência do Laboratório de áreas temáticas e/ou áreas de intervenção sobre família e/ou trabalho com elas, pode ser organizado a partir dos períodos que as/os discentes já estejam inseridos no estágio. Os laboratórios podem se constituir com carga horária menor como, por exemplo, dois créditos por semana (3oh semestrais) e se caracterizarem um espaço privilegiado para a relação teórico-prática. Além disso, podem ser ministrados como são as oficinas de estágio supervisionado.

$\mathrm{Na}$ lógica das diretrizes, tais componentes precisam ter caráter mais participativo, envolvendo as/os discentes na construção do conhecimento, das reflexões e das elaborações. Por isso, apesar da possibilidade de contarmos com as referências teóricas, é indicado o uso dos mais variados recursos pedagógicos, tais como: filmes, documentários, muralismo, músicas etc. ${ }^{11}$. Outra possibilidade é a participação de assistentes sociais que exercem o trabalho com famílias. Além do mais, nas experiências do laboratório, visitas às instituições nas quais as assistentes

\footnotetext{
${ }^{11}$ Como um potencial espaço de alternativas metodológicas indicamos documentários/filmes/séries que podem ser trabalhados tanto nos laboratórios como nas disciplinas: Séries: Anne with an E, A casa das flores. Filmes: A excêntrica família de Antônia, Eu, Daniel Blake, A Família Bélier, Kramer vs. Kramer. Documentários: 'Dandara: enquanto morar for um privilégio, ocupar é um direito', Quando a casa é a rua, Quilombo Família Silva, Uma História Severina.
}

Temporalis, Brasília (DF), ano 40, n. 20, p. 144-164, jul./dez.2020. | ISSN 2238-1856 
sociais realizem o trabalho com famílias é uma excelente estratégia. As visitas devem ser combinadas com as profissionais, assim as/os discentes passariam um tempo -deve ser decidido coletivamente - como "duas tardes" na instituição, por exemplo. Isso possibilita uma troca das discentes com a realidade profissional, diversificando as experiências de aproximação com a realidade para além do estágio.

Da mesma forma, é interessante que a experiência de laboratório proponha trabalhos coletivos ao final de cada semestre. Partindo do pressuposto de que as turmas de laboratórios são turmas menores - quando ofertadas ao mesmo tempo diversos laboratórios temáticos - é possível a construção de murais na universidade de temas discutidos; a elaboração de relatório final coletivo pela turma que apresente os principais pontos debatidos e as reflexões realizadas ao longo do semestre; elaboração de artigos individuais ou em grupos; finalização do laboratório com evento envolvendo pessoas de referências nas temáticas, profissionais envolvidas ao longo do semestre. Em nossa experiência ao discutirmos a diversidade familiar e o trabalho profissional também já optamos pela produção de vídeos/curtas, elaborado por grupos de alunos, como avaliação final.

Nas experiências do laboratório é possível a ementa ser aberta como forma de contemplar maiores proximidades com as/os docentes que se dispõem a ofertá-lo, mas também como estratégia de construção coletiva, com base nas demandas concretas. Desde que a ementa garanta a condução, ao longo do semestre, desse componente curricular com as metodologias diversas, sejam reflexivas e abordem as discussões do trabalho profissional de assistentes sociais, aqui particularmente com famílias, como central.

A partir da lógica das diretrizes, espera-se que as disciplinas, laboratórios e demais espaços formativos visem trabalhar a temática família e/ou o trabalho com famílias através da nucleação. Portanto, no caso de uma disciplina sobre família, deve haver, no seu ementário, os três núcleos de fundamentação (vida social, formação sóciohistórica, trabalho profissional), visando direcionamento da discussão, por meio dos fundamentos do Serviço Social brasileiro.

Sendo assim, a problematização e o estudo da categoria família e seus conceitos possibilitam elementos salutares para o entendimento das questões sociais, econômicas e culturais. Busca, também, o desvendamento de como os aspectos universais se particularizam de modo objetivo e subjetivo na produção e reprodução social das diversas frações de classes atendidas por nós.

Por fim, ao pensar o trabalho com famílias, além dos elementos já trabalhados ao longo do texto, é importante: desnaturalizar o trabalho desenvolvido na família e pela família; reforçar a compreensão que a dinâmica familiar não pode ser circunscrita ao âmbito das relações familiares, nem em modelos ideais, mas antes a sociabilidade e a totalidade social; a trajetória do trabalho com famílias e as formas de concebê-las ao longo da nossa história; a urgência de construirmos alternativas no trabalho com famílias pautado das necessidades delas e não pelos problemas

Temporalis, Brasília (DF), ano 40, n. 20, p. 144-164, jul./dez.2020. | ISSN 2238-1856 
apresentados, fugindo a lógica dos 'casos de família'; o enfrentamento das tendências técnico-burocráticos; psicossocial-individualizante (MIOTO, 2004).

\section{REFLEXÕES FINAIS}

O tempo presente é perpassado por grandes transformações societárias, geradas da crise estrutural do capital, expandindo-se desde a década de 1970, impactando, diretamente, todos os âmbitos da vida social, inclusive, das profissões. Nesse espectro, é preciso estarmos atentos e fortes, sobretudo, diante as novas demandas colocadas para a profissão e os tensionamentos postos à formação.

Referente à temática da família, há uma peleja no que tange aos levantamentos realizados nos estudos e nas pesquisas. Nos últimos anos, passamos da ausência nas reflexões e nas produções teóricas da temática para a retomada das publicações e das produções, processo ocorrido com contradições. Os fundamentos que subjazem o debate nem sempre apresentam consonância ao projeto profissional de formação em vigor.

Nesse sentido, entendemos que os esforços do presente ensaio podem contribuir, diretamente, no reforço da compreensão do projeto de formação do Serviço Social e, concomitantemente, ao acúmulo crítico do debate da família. Nosso pressuposto durante o texto para a formação profissional, pesquisas, grupos de pesquisa, é o de que a família, enquanto uma categoria, um complexo, deve ser estudada a partir das categorias de contradição e totalidade social. Isso exige, conforme apontou Lênin, "Para conhecer realmente um objeto, é preciso apreender e pesquisar todos os seus aspectos, todas as conexões e 'mediações'. Jamais conseguiremos fazer isso plenamente, mas a exigência de considerar todos os lados nos preservará de erros e da estagnação" (LÊNIN apud LUKÁCS, 2012, p.159).

Na direção explicitada por Lênin, é preciso apreender todos os aspectos da família e isso exige, no tempo presente, desvendar, minimamente, sua gênese e sua natureza, a particularidade assumida no modo de produção capitalista e apontarmos caminhos para a instituição - seu futuro - junto a outro projeto societário. Conforme já apontamos, tais pressupostos serão capazes de enfrentar na formação - e no trabalho - os preconceitos mais enraizados, o conservadorismo em relação a instituição, já que cabe este papel à formação profissional na direção do projeto ético político.

\section{REFERÊNCIAS}

ABEPSS. Lei de diretrizes curriculares. Rio de Janeiro: ABEPSS, 1996.

ALMEIDA, M. da S. Diversidade humana e racismo: notas para um debate radical no serviço social. Argumentum, Vitória, v.9, n.1, p.32-45, 2017. DOI:

10.18315/argum.vgi1.15764. Disponível em:

https://periodicos.ufes.br/argumentum/article/view/15764. Acesso em: 29 out. 2020. 
CFESS. O que é preconceito? Brasília, DF: CFESS, 2016. (Série Assistente Social no Combate ao Preconceito, caderno 1).

COSTA, J. F. Ordem médica e norma familiar. Rio de Janeiro: Graal, 2004.

DAVIS, A. Mulheres, raça e classe. 1. ed. São Paulo: Boitempo, 2016.

DESIDERI, L. Do discurso à prática: o que o governo Bolsonaro fez em defesa da família. Gazeta do Povo, Brasília, DF, 24 dez. 2019. Disponível em:

https://www.gazetadopovo.com.br/vida-e-cidadania/o-que-bolsonaro-fez-na-defesada-familia-2019. Acesso em: 06/07/2020.

ENGELS, F. A origem da família, da propriedade privada e do Estado. São Paulo: Expressão Popular, 2012.

EURICO, M. C. Preta, preta, pretinha: o racismo institucional no cotidiano de crianças e adolescentes negras(os) acolhidas(os). Tese (Doutorado em Serviço Social) - Pontifícia Universidade Católica de São Paulo, São Paulo, 2018.

FALQUET, J. Três questões aos movimentos sociais "progressistas": contribuições da teoria feminista à análise dos movimentos sociais. Revista Lutas \& Resistências, Londrina, v.1, p.212-225, set. 2006.

GOLDANI, A. M. As famílias no Brasil contemporâneo e o mito da desestruturação. Cadernos Pagu, Campinas, SP, n. 1, p. 68-110, 2005. Disponível em: https://periodicos.sbu.unicamp.br/ojs/index.php/cadpagu/article/view/1681. Acesso em: 30 out. 2020.

GUERRA, Y. Desafios para o serviço social na seguridade social: formação nas políticas ou para as políticas sociais? In: GUERRA, Y; LEITE, J. L; ORTIZ, F. G. (org.). Temas contemporâneos em serviço social: uma análise de seus fundamentos. Campinas: Papel Social, 2019.

HORST, C. H. M. Família, marxismo e serviço social: desvendando o invólucro místico. Tese (Doutorado em Serviço Social) - Universidade Federal de Santa Catarina, Florianópolis, 2018.

HORST, C. H. M.; MIOTO, R. C. T. Serviço social e o trabalho com famílias: renovação e conservadorismo? Revista Em Pauta, Rio de Janeiro, n. 40, 2017.

HORST, C. H. M. et al. O familismo na política social: aproximações com as bases da formação sócio-histórica brasileira. In: ENCONTRO NACIONAL DE PESQUISADORES EM SERVIÇO SOCIAL, 16., Vitória. Anais [...]. Vitória: ABEPSS, 2018.

IAMAMOTO, M. V. Renovação e conservadorismo no serviço social: ensaios críticos. 12. ed. São Paulo: Cortez, 2013. 
IAMAMOTO, M. V. A formação acadêmico-profissional no serviço social brasileiro. Serviço Social e Sociedade, São Paulo, n. 120, p. 609-639, out./dez. 2014.

LIMA, K. Universidade pública e contrarrevolução: da "travessia de uma ponte" ao "caminho da prosperidade". Em pauta, Rio de Janeiro, 2. sem. n. 44, v. 17, p. 15-32. 2019 .

LÚKÁCS, G. Para uma ontologia do ser social I. São Paulo: Boitempo, 2012.

MARINI, R. M. Dialética da Dependência. In: STEDILE, J. P.; TRASPADINI, R. (Org.). Ruy Mauro Marini: Vida e Obra. São Paulo: Expressão Popular, 2011. p. 137-180.

MÉSZÁROS, I. Para além do capital: rumo a uma teoria da transição. São Paulo: Boitempo. 2002.

MIOTO, R. C. T. Política social e trabalho familiar: questões emergentes no debate contemporâneo. Revista Serviço Social e Sociedade, São Paulo, n. 124, p. 699-720, out./dez. 2015.

MIOTO, R. C. T. Família, trabalho com famílias e serviço social. Serviço Social em Revista, Londrina, v. 12, n.2, p. 163-176, jan./jun. 2010.

MIOTO, R. C. T. Trabalho com famílias: um desafio para os assistentes sociais. Revista Textos \& Contextos, n. 3, dez. 2004.

NETTO, J. P. O Serviço social e a tradição marxista. Revista Serviço Social e Sociedade. Ano X. n. 30. maio/ago. 1989.

NISIIDE, A. C. B.; BATISTA, M. I. F. C. e S. O protagonismo político das famílias de um CAPS. Argumentum, Vitória, v. 11, n. 1, p. 160-172, 2019. DOI:

10.18315/argumentum.v1111.21680. Disponível em:

https://periodicos.ufes.br/argumentum/article/view/21680. Acesso em: 28 out. 2020.

SILVA, L. M. M. R. Serviço social e família: a legitimação de uma ideologia. 2. ed. São Paulo: Cortez, 1982.

SILVA, A. I. C da; AMARAL, A. S. do. Regressividade no direito à educação, tendências pedagógicas do EAD e serviço social brasileiro. Revista Ser Social, v. 21, n. 45, p. 435-455, 31 jul. 2019.

SILVEIRA JUNIOR, A. A. A assistência social e as ideologias do social liberalismo: tendências político-pedagógicas para a formação dos trabalhadores do SUAS. Tese (Doutorado em Serviço Social) - Universidade Federal de Pernambuco, Recife, 2016.

TEIXEIRA, R. J. Fundamentos do serviço social: uma análise a partir da unidade dos núcleos de fundamentação das diretrizes curriculares da ABEPSS. Tese (Doutorado em Serviço Social) - Universidade Federal de Rio de Janeiro, Rio de Janeiro, 2019. 
VASCONCELOS, A. M. A/O Assistente Social na Luta de Classes - Projeto Profissional e Mediações Teórico-Práticas. 1.ed. São Paulo: Cortez, 2015.

\section{Claudio Henrique Miranda Horst}

Assistente Social. Professor do Departamento de Serviço Social da Universidade Federal de Ouro Preto. Doutor em Serviço Social (UFSC). Mestre em Política Social (UFES). Membro do "Livre Hermana" - Núcleo de Estudos e Pesquisas sobre Formação Social Latino-Americana e Brasileira e do Núcleo de Extensão e Estudos em Formação e Trabalho em Serviço Social (NEESFT). 